Tropical Journal of Pharmaceutical Research October 2019; 18 (10): 2155-2160

ISSN: $1596-5996$ (print); 1596-9827 (electronic)

(C) Pharmacotherapy Group, Faculty of Pharmacy, University of Benin, Benin City, 300001 Nigeria.

Available online at http://www.tjpr.org

Original Research Article

http://dx.doi.org/10.4314/tjpr.v18i10.22

\title{
Phytochemical profiling of Costus (Saussurea lappa Clarke) root essential oil, and its antimicrobial and toxicological effects
}

\author{
Siddig Ibrahim Abdelwahab ${ }^{1 *}$, Manal Mohamed Elhassan Taha ${ }^{2}$, Hassan \\ Ahmed Alhazmi ${ }^{1,3}$, Waquar Ahsan ${ }^{3}$, Zia ur Rehman ${ }^{3}$, Mohammed Al Bratty ${ }^{3}$, \\ Hafiz Makeen ${ }^{4}$ \\ ${ }^{1}$ Substance Abuse Research Centre, Jazan University, PO Box $114,{ }^{2}$ Biomedical Research Unit, Medical Research Centre, \\ Jazan University, ${ }^{3}$ Department of Pharmaceutical Chemistry, College of Pharmacy, Jazan University, ${ }^{4}$ Department of Clinical \\ Pharmacy, College of Pharmacy, Jazan University, Jazan 45142, Saudi Arabia
}

*For correspondence: Email: siddigabdlewahab.sarc@gmail.com; Tel: 00966-506612390

Sent for review: 27 March 2019

Revised accepted: 17 September 2019

\begin{abstract}
Purpose: To carry out gas chromatography-mass spectrometry (GC-MS) analysis of the phytochemical content of the root essential oil of Saussurea lappa Clarke Asteraceae (Costus, SLEO), and to evaluate its physicochemical, antimicrobial and cytoxic properties.

Methods: The oil was extracted from the plant's roots by steam distillation using a Clevenger system. Various physicochemical parameters for the oil including refractive index, color, acid value, saponification number, ester and peroxide values were measured. Flavonoid content was assessed using thin layer chromatography (TLC). Thermoscientific trace ultra gas chromatograph equipped with a Thermoscientific capillary TR-5MS column was utilized to determine the volatile components of SLEO. Antimicrobial activity of SLEO was performed against various Gram (+ve) and Gram (-ve) microorganisms, viz, Bacillus subtilis, Staphylococcus aureus, Escherichia coli, Pseudomonas aeruginosa and Candida albicans, while cytotoxic effect was monitored using Artemia salina (brine shrimp) lethality assay.

Results: Essential oil yield was good (3\%). Concentration-dependent antimicrobial effects were observed on all test microorganisms and no marked difference in lethality levels was observed among the tested SLEO concentrations on brine shrimp $(p<0.05)$. The main component of SLEO was costunolide or eudesma-5,11(13)-dien-8,12-olide (52.01\%).

Conclusion: The results indicate the promising therapeutic properties of S. lappa. However, further phytochemical and biological investigations are required to establish the mechanism of action and toxicological the extract.
\end{abstract}

Keywords: Saussurea lappa; Antimicrobial, Essential oil, Brine shrimp lethality

This is an Open Access article that uses a fund-ing model which does not charge readers or their institutions for access and distributed under the terms of the Creative Commons Attribution License (http://creativecommons.org/licenses/by/4.0) and the Budapest Open Access Initiative (http://www.budapestopenaccessinitiative.org/read), which permit unrestricted use, distribution, and reproduction in any medium, provided the original work is properly credited.

Tropical Journal of Pharmaceutical Research is indexed by Science Citation Index (SciSearch), Scopus, International Pharmaceutical Abstract, Chemical Abstracts, Embase, Index Copernicus, EBSCO, African Index Medicus, JournalSeek, Journal Citation Reports/Science Edition, Directory of Open Access Journals (DOAJ), African Journal Online, Bioline International, Open-J-Gate and Pharmacy Abstracts

\section{INTRODUCTION}

Essential oils from herbal sources possess versatilerevealed presence of several important constituents. aromatic and medicinal properties and have beenSaussurea lappa Clarke (Family: Compositae), 
locally known as Costus or kuth, is native to South[10]. Thin layer chromatography was utilized for Asia [2]. Essential oils from the roots of this plantthe determination of flavonoid content [11]. are utilized intensively in conventional medicine [3].

As a folklore medicine, this plant has been used in a Gas chromatography-mass spectrometry variety of conditions, including convulsion, duodenal(GC-MS)

ulcer, tumors, liver injuries, arthritis and microbial

infections $[4,5]$. These traditional uses were mainlyGC-MS analysis of SLEO was performed using reported in India and Arabic region [5]. A reviewThermoscientific trace ultra Gas Chromatograph published by Bajrai in 2010 reported that this plant(Thermo Fisher Scientific, MA) equipped with a is used in Saudi Arabia for the treatment of femaleThermoscientific capillary TR-5MS column (30 m complaints, carminative and cough [6]. It has also $\times 0.25 \mathrm{~mm} \mathrm{ID} \times 0.25 \mu \mathrm{m})$. For GC-MS detection, been used for the treatment of tonsillitis in childrenan electron ionization system with ionization [7]. Saussurea lappa contains various compoundsenergy $70 \mathrm{eV}$ was used. Helium was used as the including costunolide and isodihydrocostunolidescarrier gas at a constant flow rate of $1.0 \mathrm{~mL} / \mathrm{min}$. which are known to be biologically active andInjector and MS transfer line temperature were promising resource for developing new medicationsset at 260 and $270{ }^{\circ} \mathrm{C}$ respectively. The oven [4].

temperature was held at $50^{\circ} \mathrm{C}$ for 5 min initially, then ramped at $5{ }^{\circ} \mathrm{C} / \mathrm{min}$ to $140{ }^{\circ} \mathrm{C}$ and finally Owing to its diverse and important biologicalraised to $280^{\circ} \mathrm{C}$ at $3^{\circ} \mathrm{C} / \mathrm{min}$ increase. A volume activities, $S$. lappa has shown to have substantial of $1 \mu \mathrm{L}$ of the diluted sample $(1 / 100, \mathrm{v} / \mathrm{v}$ in possibility to emerge as a new drug. Antimicrobialmethanol) was injected by Autosampler A1/AS agents obtained from plant sources are presently 3000 using split less mode. The relative contributing to human health. Previously,percentage abundance of each component was antibacterial, antiviral, antifungal and antiprotozoalcalculated by comparing its average peak area to studies carried out on $S$. lappa collected from otherthe total area of all components. Mass regions, have revealed promising results [8]. Thisspectrometer coupled to thermo GC-MS ultra led to the present investigation of the essential oilsystem was set to scan time $0.6 \mathrm{sec}$ and mass obtained from the root of $S$. lappa obtained fromrange $50-800$ amu. X-Calibur software was southern Saudi Arabia against various bacterial andused to interpret mass spectra and fungal strains. No previous reports have shown thechromatograms and the fragmentation patterns biological activities of $S$. lappa root essential oilof mass spectra were compared with those (SLEO) extracted from the plants used in Saudistored in the spectrometer database using Arabia. the NIST, MAINLIB and REPLIB built-in libraries.

\section{EXPERIMENTAL}

\section{Extraction of essential oil}

The plant roots were collected from an exclusive shop in Jazan, Saudi Arabia. Oil extraction was performed on $400 \mathrm{~g}$ coarsely powdered roots by steam distillation using Clevenger system, operated for $3 \mathrm{~h}$. The aqueous residue obtained was extracted with dichloromethane $(3 \times 50 \mathrm{~mL})$ and the combined organic phase was dried with sodium sulphate, filtered and the evaporated under reduced pressure until dryness. The Stock of SLEO obtained was kept in the refrigerator till further use.

\section{Determination of physiochemical properties}

The refractive index and density of $S$. lappa essential oil (SLEO) were measured using standard methods [9]. A digital refractometer (Mettler Toledo, Columbus, USA) was used for the determination of refractive index of oil. Standard procedures were followed for the determination of color, acid value, saponification number, ester value and peroxide value of the oil

\section{Antimicrobial activity}

The paper disc diffusion method was used to screen the antibacterial activity of SLEO and performed by using Mueller Hinton agar (MHA) medium. The experiment was carried out according to the National Committee for Clinical Laboratory Standards Guidelines [12]. Bacterial suspension was diluted with sterile physiological solution to $10^{8} \mathrm{cfu} / \mathrm{mL}$ (turbidity = McFarland standard 0.5). An aliquot of $100 \mu \mathrm{L}$ of bacterial suspension was swabbed uniformly on surface of MHA and the inoculum was allowed to dry for 5 min. Sterilized filter paper discs (Whattman No.1, $6 \mathrm{~mm}$ in diameter) were placed on the surface of MHA and soaked with $20 \mu \mathrm{L}$ solutions of each SLEO concentration prepared in DMSO. The inoculated plates were incubated at $37^{\circ} \mathrm{C}$ for 24 $\mathrm{h}$ in the inverted position. The diameters $(\mathrm{mm})$ of the inhibition zones were measured. Tested microorganisms were four bacterial strains Bacillus subtilis (NCTC 8236, Gram +ve), Staphylococcus aureus (ATCC 25923, Gram $+v e$ ), Escherichia coli (ATCC 25922, Gram -ve), Pseudomonas aeruginosa (ATCC 27853, Gram ve) as well as two fungal strains, Aspergillus 
niger (ATCC9763) and Candida albicans (ATCC7596).

\section{Brine shrimp lethality assay}

Bio-safety and possible cytotoxicity of SLEO was monitored using the Artemia salina (brine shrimp) lethality assay [13]. Approximately, $50 \mathrm{mg}$ of $A$. salina (leach) eggs were added to a hatching chamber containing artificial sea water $(75 \mathrm{~mL})$. The hatching chamber was kept under an inflorescent bulb for $48 \mathrm{~h}$ for the eggs to hatch into shrimp larvae. Accurately weighed quantity (20 mg) of SLEO was dissolved in $2 \mathrm{~mL}$ methanol, and 500,50 and $5 \mu \mathrm{L}$ of the resulting solution were transferred to vials corresponding to 1000,100 and $10 \mu \mathrm{g} / \mathrm{mL}$ concentrations respectively. Ten larvae of $A$. salina leach (taken 48 to $72 \mathrm{~h}$ after the initiation of hatching) were added to each vial and the final volume of solution in e-ach vial was adjusted to $5 \mathrm{~mL}$ with sea water immediately after adding the shrimps. One drop of dimethylsulphoxide (DMSO) was added to the test and control vials before adding the shrimps to enhance the solubility of test materials. Each dose was tested in triplicate.

\section{Statistical analysis}

Data were statistically analyzed using SPSS (IBM Inc, USA) version 20 software and are reported as mean \pm standard error of mean (SEM). Differences between groups were accordingly assessed with the suitable inferential statistical test. $p$-value of less than 0.05 was considered as a border type-1 error.

\section{RESULTS}

\section{Physiochemical properties}

Various physicochemical properties of the essential oil were determined and the values obtained are summarized in Table 1. It was obtained as a reddish yellow liquid in good yield

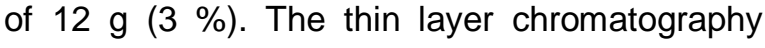

(TLC) analysis showed presence of flavonoids in high concentration.

Table 1: Physiochemical properties of Saussurea lappa root essential oil

\begin{tabular}{ll}
\hline Parameter & Value \\
\hline Yield & $3 \%$ \\
Specific density & 0.0479 \\
Refractive index & 15.5 \\
Color & Reddish yellow \\
Acid value $(\mathrm{mg} \mathrm{KOH} / \mathrm{g})$ & $19.63: 5$ \\
Saponification number & 130.4007 \\
Ester value & 110.8172 \\
Peroxide value & 2.5 \\
Flavonoid & +++ \\
\hline
\end{tabular}

\section{Antimicrobial activity}

The antibacterial activity of SLEO was tested against strains of $E$. coli, $P$. aeruginosa, $S$. aureus and $B$. subtilis using paper disc diffusion method. The inhibition zone diameter (Mean \pm SEM) was used to measure the efficacy of SLEO as antimicrobial agent. $A$ concentration dependent antibacterial effect was observed on all tested bacterial strains. The fungal strain $C$. Albicans was also susceptible to SLEO and this effect was also dose-dependent as shown in Table 2.

\section{Cytotoxicity}

Brine shrimp (Artemia salina) lethality assay was performed to test the toxicity of SLEO and the results obtained are shown in Figure 1. S. lappa essential oil showed no major difference in the lethality levels at various concentrations tested. When tested at high concentration $(1000 \mu \mathrm{g} / \mathrm{mL})$, it showed $A$. salina larvae mortality rate of $13 \%$.

\section{Phytochemical composition of SLEO}

Gas chromatography-mass spectrometry analysis of the SLEO was carried out using an improved method and different peaks corresponding to various constituents were obtained in the GC spectra as depicted in Figure 2.

Table 2: Antimicrobial activities of Costus roots essential oil (Saussurea lappa Clarke)

\begin{tabular}{|c|c|c|c|c|c|}
\hline \multirow{2}{*}{$\begin{array}{l}\text { Conc. of SLEO } \\
(\mu \mathrm{g} / \mathrm{mL})\end{array}$} & \multicolumn{5}{|c|}{ Zone of inhibition (mm, mean \pm SEM } \\
\hline & E. coli & P. aeruginosa & S. aureus & B. subtilis & C. albicans \\
\hline DMSO & -- & -- & -- & -- & -- \\
\hline 6.25 & $16 \pm 0.89$ & $14 \pm 0.4$ & $20 \pm 2.8$ & $20 \pm 0.2$ & $12 \pm 1.7$ \\
\hline 12.5 & $17 \pm 1.8$ & $14 \pm 0.8$ & $25 \pm 0.9$ & $21 \pm 0.6$ & $13 \pm 0.5$ \\
\hline 25 & $18 \pm 2.5$ & $15 \pm 2.7$ & $27 \pm 1.4$ & $21 \pm 1.8$ & $14 \pm 2.6$ \\
\hline 50 & $19 \pm 0.9$ & $16 \pm 0.9$ & $28 \pm 2.4$ & $22 \pm 2.1$ & $14 \pm 1.9$ \\
\hline 100 & $21 \pm 1.2$ & $17 \pm 1.1$ & $29 \pm 5.2$ & $25 \pm 2.8$ & $15 \pm 1.1$ \\
\hline
\end{tabular}




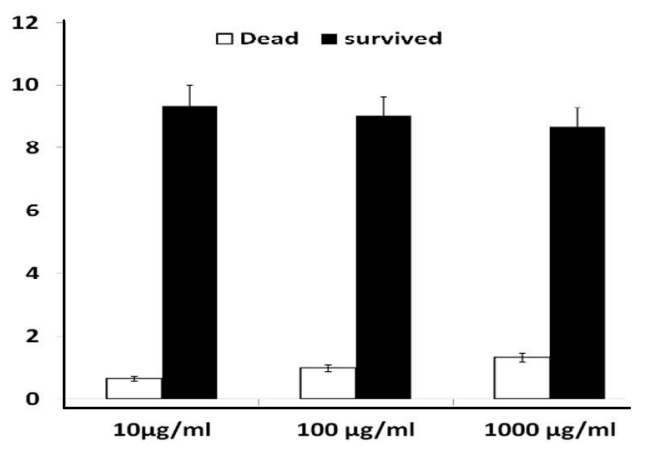

Figure 1: Brine shrimp lethality of Costus roots essential oil (Saussurea lappa Clarke). Brine shrimp were incubated at 10 shrimps/vial. Various concentrations of SLEO were tested and number of dead and survived larvae of $A$. salina was obtained

The major components of SLEO are listed in Table 3. Costunolides, which is chemically, Eudesma-5,11(13)-dien-8,12-olide (52.01 \%; Figure 3), was the major compound detected in SLEO followed by elemene (7.18\%), phenanthrenone $(2.97 \%)$, caryophyllene oxide (2.39\%), 9,12-octadecadienoic acid (Z,Z)-(2.13 $\%)$, cyclohexane (2.12 \%), germacra-1(10), 4,11(13)-trien-12-oic acid, 6a-hydroxy-,y-lactone, (E,E)- (1.96 \%), androstan-17-one, 3-ethyl-3hydroxy-,(5à)- (0.82\%), bicyclo[10.1.0]tridec-1ene $(0.81 \%)$, naphthalene $(0.74 \%)$, cedren-13ol,8- $(0.62 \%)$ and 4a,8-dimethyl-2-(prop-1-en-2yl)-1,2,3,4,4a,5,6,7-octahydronaphthalene $(0.47$ $\%)$. Minor Compounds with less than $0.4 \%$ were not reported.

\section{DISCUSSION}

Physiochemical properties, spectroscopic investigations, antimicrobial assay and lethality test were conducted to characterize and evaluate theFigure 3: Major components detected in the essential biological activities of the essential oil of Saussurea $a^{\text {oil of Saussurea lappa }}$

lappa roots. Physiochemical properties of SLEO investigated in this study included specific density,

Table 3: The major components of Costus roots essential oil (Saussurea lappa Clarke)

\begin{tabular}{lcc}
\hline Compound & Area (\%) & $\begin{array}{c}\text { Retention time } \\
\text { (min) }\end{array}$ \\
\hline Eudesma-5,11(13)-dien-8,12-olide & 52.01 & 45.30 \\
Elemene & 7.18 & 48.21 \\
Phenanthrenone & 2.97 & 46.11 \\
Caryophyllene oxide & 2.39 & 42.27 \\
9,12-Octadecadienoic acid (Z,Z)- & 2.13 & 52.20 \\
Cyclohexane & 2.12 & 23.76 \\
Germacra-1(10),4,11(13)-trien-12-oic acid,6à-hydroxy-,ç-lactone, (E,E)- & 1.96 & 43.84 \\
Androstan-17-one, 3-ethyl-3-hydroxy-, (5à)- & 0.82 & 41.68 \\
Bicyclo[10.1.0]tridec-1-ene & 0.81 & 34.81 \\
Naphthalene & 0.74 & 27.42 \\
Cedren-13-ol, 8- & 0.62 & 35.00 \\
4a,8-Dimethyl-2-(prop-1-en-2-yl)-1,2,3,4,4a,5,6,7-octahydronaphthalene & 0.47 & 26.71 \\
\hline
\end{tabular}


Polyphenolic content of extracts and oils of plant origin have shown tremendous biological and economic values in the past. Awareness regarding emerging natural nutritional antioxidants is rising due to their well-recognized impact on human wellbeing. The current study also investigated the flavonoid content of SLEO using TLC analysis which showed high content of flavonoids. Previous research showed that the $S$. lappa extract possesses alkaloids, carbohydrates, glycosides, phenolic compounds and saponins [15]. The brine shrimp lethality assay represents a quick, low-priced and straight-forward bioassay for the investigation of safety related to plant products. The findings of the toxicity assay of SLEO using brine shrimp revealed no significant difference in the lethality levels at the concentrations tested with $13 \%$ mortality rate of the $A$. salina larvae at the highest concentration $(1000 \mu \mathrm{g} / \mathrm{mL})$ tested. The results obtained suggested the safety of SLEO use on human beings with no or little cytotoxic effects expected. However, further studies are required to establish the safety of SLEO on human. Disc diffusion assay is one of the most commonly used techniques for the assessment of antibacterial properties of medicinal plants. This method had already been used elsewhere to assess the antibacterial activity of $S$. lappa roots extract previously [18]. However, this recognized and reliable technique was re-applied to examine the antimicrobial activities of the obtained SLEO sample using two gram positive strains, B. subtilis and $S$. aureus; two gram negative strains, $E$. coli and $P$. aeruginosa and two fungal strains, $A$. niger and $C$. albicans. Concentration dependent antibacterial effects were observed on all the tested microbes. Acylated flavone glycosides were detected in the roots of the $S$. lappa and these glycosides are known to be the reason of antifungal activity of this plant [18]. Major components of SLEO represented $74.22 \%$ of the total oil. The chemical composition of the essential oil of $S$. lappa essential oil was similar to that reported in other studies [17]. In this study, the essential oil from the roots was obtained in higher yield $(3 \%)$ than previous studies. Two previous studies reported that the hydro-distillation of S. lappa (roots) yielded oil at $0.23 \%$ [18] and $0.89 \%$ [17] $(\mathrm{v} / \mathrm{w})$, respectively. Preceding GC-MS analysis of extracted essential oil of $S$. lappa showed presence of sesquiterpenes, among these, $\beta$ castol and $\delta$-elemene were found as major components [18]. However, the chemical composition of the SLEO obtained in this study showed some dissimilarity from other reported studies, which may be due to time of harvesting, local, climatic and seasonal issues as well as the storage time of plant roots.

\section{CONCLUSION}

The extracted SLEO in this study showed different type and concentration of chemical constituents than the oil from other reported studies. It suggested that the oil composition depends upon a variety of environmental factors. The results of antimicrobial and toxicity studies supported the presence of active antimicrobial chemical constituents in SLEO with lesser toxicity. Additional studies are required to establish the mechanism of its antimicrobial effects and toxicity on other living systems. This may lead to the development of new plant based antimicrobial drug which could combat the problem of microbial resistance with lesser toxicity to the host.

\section{DECLARATIONS}

\section{Acknowledgement}

The authors wish to express their utmost gratitude to Deanship of Scientific Research, Jazan University for funding this work through Ethnopharmacology Research Group (RG-2-7).

\section{Conflict of interest}

No conflict of interest is associated with this work.

\section{Contribution of authors}

We declare that this work was done by the authors named in this article and all liabilities pertaining to claims relating to the content of this article will be borne by the authors.

\section{Open Access}

This is an Open Access article that uses a funding model which does not charge readers or their institutions for access and distributed under the terms of the Creative Commons Attribution License (http://creativecommons.org/licenses/by/ 4.0) and the Budapest Open Access Initiative (http://www.budapestopenaccessinitiative.org/rea d), which permit unrestricted use, distribution, and reproduction in any medium, provided the original work is properly credited.

\section{REFERENCES}

1. Rani $C$, Chawla $S$, Mangal M, Mangal A, Kajla $S$, Dhawan A. Nyctanthes arbor-tristis Linn. (Night Jasmine): A sacred ornamental plant with immense 
medicinal potentials. Indian J Trad Know 2012; 11: 427435.

2. Cho JY, Baik $K U$, Jung JH, Park MH. In vitro antiinflammatory effects of cynaropicrin, a sesquiterpene lactone, from Saussurea lappa. Eur J Pharmacol 2000; 398: 399-407.

3. Gautam H, Asrani R. Phytochemical and Pharmacological Review of an Ethno Medicinal Plant: Saussurea Lappa. Vet Res 2018; 6: 1-9.

4. Ansari S, Siddiqui MA, Maaz M. Hepatocurative effect of Saussurea lappa CB Clarke and Artemisia absinthium, Linn in chronic hepatitis B. J Young Pharm 2018; 10: 354-357.

5. Pradhan SK, Gupta RC, Goel RK. Comparative highperformance thin-layer chromatography profiling of Saussurea lappa and Saussurea auriculata. JPC-J Planar Chromat 2018; 31: 332-336.

6. Bajrai AA. Prevalence of crude drugs used in Arab folk medicine available in Makkah AllMukarramah Area. Int J Med Med Sci 2010; 2: 256-262.

7. Nayak $V$, Jadhav $V$, Sajjanshetty $M$. Traditional medicine in the management of recurrent tonsillitis-An ayurvedic perspective. J Ayurveda Integr Med Sci 2018; 2: 98-106.

8. Rempe CS, Burris KP, Lenaghan SC, Stewart CN. The potential of systems biology to discover antibacterial mechanisms of plant phenolics. Front Microbiol 2017; 8: 422.

9. de Almeida $A A C$, de Carvalho RBF, Silva $O A$, de Sousa $D P$, de Freitas RM. Potential antioxidant and anxiolytic effects of (+)-limonene epoxide in mice after marbleburying test. Pharmacol Biochem Behav 2014; 118: 6978.
10. Chowdhury A, Kapoor V. Essential oil from the fruit of Apium graveolens. J Med Aromat Plant Sci 2000; 22(1B): 621-623.

11. El-Olemy MM, Al-Muhtadi FJ, Afifi AFA. Experimental Phytochemistry: A Laboratory Manual, King Saud University Press, Riyadh; 1994; $16 p$.

12. Kiehlbauch JA, Hannett GE, Salfinger M, Archinal W, Monserrat C, Carlyn C. Use of the National Committee for Clinical Laboratory Standards guidelines for disk diffusion susceptibility testing in New York state laboratories. J Clin Microbiol 2000; 38: 3341-3348.

13. Fatope $M$, Ibrahim $H$, Takeda $Y$. Screening of higher plants reputed as pesticides using the brine shrimp lethality assay. Int $J$ Pharmacogn 1993; 31: 250-254.

14. Liu ZL, He Q, Chu SS, Wang CF, Du SS, Deng ZW. Essential oil composition and larvicidal activity of Saussurea lappa roots against the mosquito Aedes albopictus (Diptera: Culicidae). Parasitol Res 2012; 110: 2125-2130.

15. Chandur U, Shashidhar S, Chandrasekar S, Bhanumathy M, Midhun T. Phytochemical evaluation and anti-arthritic activity of root of Saussurea lappa. Pharmacologia 2011; 2: 265-267.

16. Irshad M, Mahmood $M$, Perveen F. In vitro antibacterial activities of three medicinal plants using agar well diffusion method. Res J Biol 2012; 2: 1-8.

17. Rao SK, Babu VG, Ramnareddy VY. Acylated flavone glycosides from the roots of Saussurea lappa and their antifungal activity. Molecules 2007; 12: 328-344.

18. Negi JS, Bisht V, Bhatt A, Bhatt V, Sati M, Mohanty J, Sundriyal $R$. Antidiarrheal activity of methanol extract and major essential oil contents of Saussurea lappa Clarke. Afr J Pharm Pharmacol 2013; 7: 474-477. 